\title{
Development of the India Patriarchy Index: Validation and Testing of Temporal and Spatial Patterning
}

\author{
Abhishek Singh $^{1}$ (D) Praveen Chokhandre ${ }^{2}$. Ajeet Kumar Singh ${ }^{2} \cdot$ Kathryn M. Barker $^{3}$. \\ Kaushalendra Kumar ${ }^{1} \cdot$ Lotus McDougal $^{3}$ - K. S. James ${ }^{4} \cdot$ Anita Raj $^{3}$
}

Accepted: 29 June 2021 / Published online: 9 July 2021

(c) The Author(s) 2021

\begin{abstract}
While existing indices of gender equality measure the role of women's status and position, they inadequately contextualize the broader construct of patriarchy, a social system that underlies many gender inequitable practices. An index capturing patriarchy may afford increased understanding of this social system, and may serve to complement other gender equality indices. This paper involves the development and testing of a novel composite measure, the India Patriarchy Index, to quantify the social and ideological construct of patriarchy using empirical data on family structure and gender roles. Using data from India's National Family Health Survey, we develop an India Patriarchy Index to measure gendered social positioning in families based on sex by age, patrilocality, sex ratio imbalance among offspring, and gendered economic roles. Psychometric testing demonstrates good internal reliability and construct validity of this index, with validity indicated by its association with three gender equality indices used in India. Spatial and temporal analyses further indicate much state-level variation in India Patriarchy Index scores as well as slow change on this indicator over time, based on time trend analyses from 1992-93 to 2015-16. Results demonstrate the utility of the India Patriarchy Index to measure and track gender equality progress in India.
\end{abstract}

Keywords India Patriarchy Index · National Family Health Survey $\cdot$ India

Abhishek Singh

abhishek@iipsindia.ac.in

1 Department of Public Health and Mortality Studies, International Institute for Population Sciences, Mumbai, India

2 GEH Project, International Institute for Population Sciences, Mumbai, India

3 Infectious Diseases and Global Public Health, School of Medicine, University of California San Diego, San Diego, USA

4 International Institute for Population Sciences, Mumbai, India 


\section{Introduction}

Twenty-five years ago was a tipping point in prioritizing and measuring progress on women's development at national and international levels, with the 4th Conference on Women in Beijing and the introduction of the Gender Development Index, the first ever index seeking to measure and rank nations based on gender gaps in life expectancy, education, and per capita income (UNDP, 2019). Since this time, a growing number of global indices have been designed to assess gender empowerment at the national level (Raj, 2017), built from indicators available for most national contexts. These advancements have been important in bringing recognition of national-level progress on gender equality, but they provide little insight into the role of normative and institutionally supported patriarchymale dominance over women - as an indication of ongoing inequality (Walby, 1989). From an eco-social theoretical standpoint (Krieger, 2011), an understanding of these broader social structures of patriarchy is essential if the international community is to meaningfully improve gender equality and empowerment.

Though a variety of definitions of patriarchy exist within the social sciences, a broad, working definition is as follows: "a system of social structures and practices in which men dominate, oppress and exploit women" (Walby, 1989). Patriarchal norms contribute to gender inequality, in part, by dictating that men should have priority in access to resources in the family, market, state, and society writ large (Walby, 1989). In Indian society, patriarchal ideology is formalized and enforced through laws, customs, and rituals and is evidenced by power relations within households. For example, the majority of households within India are headed by a male, with only $15 \%$ of the total number of households in India having a female head of household (IIPS and ICF, 2017). Household headship, especially for males, imparts control over familial resources and is reflective of power relations (Blumberg, 1988). These power relations extend across generations, and seniority also plays a crucial role in determining household authority. As such, the oldest male relative in a household is traditionally considered to be the household head (Gruber \& Szołtysek, 2016; Ruggles, 2015). Relatedly, sons are rarely permitted to establish their own independent households even after marriage, and, once married, women are traditionally required to live with their husbands in the home of their in-laws.

Although patriarchy manifests in multiple social spheres (e.g., political, economic, media coverage), taking a family demographic analytic approach (see, e.g., Seltzer, 2019) provides demographers and other social scientists the ability to empirically assess important insights into patriarchal power dynamics that are associated with gender inequality. This is particularly critical in the context of India where issues linked to gender inequality are deeply rooted and reinforced through norms and familial traditions (Littrell \& Bertsch, 2013; Malhotra et al., 1995; Sev'er, 2008; Vishwanath \& Palakonda, 2011). Notably, in the demographic and health sphere, this issue has received little attention, and we could only identify one study using data from India that examined the association between patriarchy and fertility (Malhotra et al., 1995). The paper was published 25 years ago and used data more than a decade prior to that. Nonetheless, it found that districts in India with higher patriarchy had higher levels of fertility, an indicator of women's primary value as child bearer. The authors measured three dimensions of patriarchy—active discrimination, marriage system, and economic value of women - via six variables: sex ratio of mortality, female literacy share, proportion of unmarried female age 15-19, excess female migration, female labor force share, and area under rice cultivation (Malhotra et al., 1995). While the authors argue that most of the indicators related to patriarchy mentioned in the literature 
fall within their three dimensions of patriarchy, their examination of the marriage system fails to capture the full familial context in which patriarchal ideologies are both created and enforced.

Although quantitative research focused on measurement of patriarchy in India has stagnated, recent analysis from Europe has examined this issue, including the context of household and family structure. Gruber and Szołtysek (2016) developed a Patriarchy Index which theorizes patriarchy as based on gendered power relations in marital and family dynamics, using demographic indicators on marital age and practices, family structure and roles by age, sex of offspring, and power relations within the household, to allow for crosscultural and cross-national analysis. The Index was conceptualized and empirically tested in the European context using historical census data and demonstrates good validity in terms of its expected associations geographically. The index has been validated via testing against several other indexes, including the Female Friendliness Index, Family Ties, Contemporary Patriarchy, Gender Inequality Index, Emancipatory Value Index, Social Institutions and Gender Index (SIGI), etc. (Szoltysek \& Poniat, ). However, it has not yet been applied outside of Europe.

The widely used indices of gender inequality in India such as the Gender Development Index (GDI), the Women's Empowerment Index (WEI), and the Gender Vulnerability Index (GVI) do not fully capture gender inequality. For example, GDI developed by the United Nations assesses gender differences in development in three areas: life expectancy, education, and estimated earned income (UNDP, 2019). While the WEI (Bansal, 2017), created in 2017 for India, assesses women's social positioning and safety, the GVI (Plan India, 2017) (also created in 2017 for India) focuses on women and girls' education, health and survival, poverty, and protection. Gender inequality in outcomes such as health and survival, education, safety, etc. are often the result of deep-rooted patriarchal norms in a country like India where these norms can determine the rights of women (Jayachandran, 2015). The construction and functional form of indices like Gender Inequality Index, GDI, and Gender Empowerment Measure (GEM) are often too confusing and complicated. Scholars have argued that these indices are an odd combination of absolute welfare levels and gender equality (Dijkstra, 2006; Permanyer, 2013). Because of these limitations, some indices of gender inequality, used earlier, are no longer used; the best example of such indicators are GEM and GDI. Newer indices such as the SIGI are evolving to fulfill the important gaps in the existing literature on gender inequality (Jäger \& Rohwer, 2009; OECD, 2019). However, it is difficult to measure these indices at the sub-national level. Ferrant and Nowacka (2015) highlight the important role played by formal and informal laws, social norms, and practices in driving gender inequality. Noted Gender Specialist Prof. Naila Kabeer has argued that patriarchy is working against India's gender inequality (Kabeer, 2015). Given the deep-rooted patriarchal norms in India and the complications and confusions arising out of existing indices of gender inequality, there is a need for an index of patriarchy that can comprehensively capture such norms prevalent in Indian society for different time points, geographies and populations.

An important advantage of the patriarchy index developed by Gruber and Szołtysek (2016) is that it can be easily estimated using Census or population-based household surveys such as Demographic and Health Surveys (DHS), which are routinely conducted at regular intervals in low- and middle- income countries (LMICs), including India (Gruber \& Szołtysek, 2016). This allows for index calculation at lower administrative levels such as districts. Indices estimated at the national and state levels in India may hide widespread within-state heterogeneity in a country as diverse as India. Moreover, unlike Malhotra et al. (1995), this approach more comprehensively captures patriarchy using four 
domains-domination of men over women, domination of the older generation over the younger generation, patrilocality, and son preference - and 11 indicators.

The present study aims to adapt and psychometrically test the Patriarchy Index developed by Gruber and Szołtysek (2016) for use in India. We use nationally-representative DHS data (the National Family Health Survey [NFHS]), and evaluate state, temporal, and socio-economic variations in India Patriarchy Index between 1992-93 and 2015-2016. We psychometrically validate our India Patriarchy Index with the GDI, as well as with two more recently developed gender empowerment measures created for India, and recognized by the Government of India, the WEI and the GVI. Finally, we examine the geographic variation of the India Patriarchy Index across the 640 districts of India. Findings from this work can offer important insight into how to measure patriarchy at scale, contribute to the broader literature aligned with Sustainable Development Goal 5: Gender Equality and Empowerment of All Women and Girls, and support ways to more comprehensively track progress against this Goal.

\section{Data and Methods}

\subsection{Data}

This study involved analysis of three out of four rounds of the NFHS, a DHS survey conducted in India in 1992-93, 2005-06, and 2015-16 to provide national and state level estimates on family structures, fertility, family planning, reproductive and child health, and the quality and use of health and welfare services. In addition, NFHS 2015-16 provides estimates for the 640 districts of India as per the 2011 Indian Census. The second round of NFHS (1998-99) was excluded as it was only 5-6 years after the 1992-93 NFHS wave. In NFHS 1992-93 data were collected from households and individual women. However, in NFHS 2005-06 and NFHS 2015-16, men were also interviewed in a sub-set of representative households (IIPS and ICF, 2017; IIPS and MacroInternational, 1995, 2007). Henceforth, NFHS 1992-93, NFHS 2005-06, and NFHS 2015-16 will be referred to as NFHS-1, NFHS-3, and NFHS-4 respectively.

NFHS-4 interviews were conducted in a total of 601,509 households from which 699,686 women age 15-49 were interviewed, representing all the 640 districts across India. NFHS-3 interviews were conducted in a total of 109,041 households from which 124,385 women age 15-49 were interviewed. NFHS-1 data were collected from 88,562 households from which 89,777 ever-married women age 13-49 years were interviewed. Survey data were collected via face-to-face interviews with a trained, sex-matched interviewer, and informed consent was obtained prior to interview. All NFHS surveys used standardized questionnaires, sample designs, and field procedures to collect data, and engaged a multistage stratified cluster sample approach to ensure representation from urban and rural areas. Sampling weights are calculated for each NFHS to provide estimates representative of India at the state and national level in NFHS-1 and NFHS-3; and for some variables, at the district levels in NFHS-4. Response rates for households and for women across all NFHS surveys included in this study were greater than $90 \%$. For further details regarding study design, sampling, tools and protocol, please see the national NFHS reports (IIPS and ICF, 2017; IIPS and Macro International, 2007; IIPS, 1995). All estimates presented in this paper are adjusted for complex survey design. 


\subsection{Ethics Statement}

The NFHS are a publicly available secondary dataset containing no personally identifiable information. These data can be accessed from the ICF website on request. Moreover, appropriate ethical approvals were obtained by the International Institute for Population Sciences (IIPS) and ICF to conduct NFHS in India.

\subsection{Measures}

The India Patriarchy Index modifies the original Patriarchy Index developed in Europe by Gruber and Szołtysek (2016) in a number of ways to adapt it to India's middle-income country context. We retain the original four domains: (1) domination of men over women, (2) domination of the older generation over the younger generation, (3) patrilocality, and (4) son preference. We however include an additional variable in the fourth domain to reflect son-preference. We defined this variable based on reports where ideal number of son(s) is greater than ideal number of daughter(s). We also excluded two measures: proportion of young women living with neither their own nor their husband's families and proportion of elderly people living with lateral relatives. The prevalence of young women living with neither their own nor their husband's families was extremely low $(0.18 \%)$ at the national level, and was close to zero in a majority of states. It was difficult to correctly identify lateral relatives in a number of cases using the NFHS data as the relationship of a member in the household roaster is in reference to the household head and not to elderly members of the household. Importantly, we have added an additional domain, (5) socioeconomic domination, with recognition of the social and economic imbalances between men and women in households, in terms of both earning and control over money and education (IIPS and ICF, 2017; IIPS and Macro International, 2007).

These five domains broadly capture a wide range of variables relating to the spheres of nuptiality and age at marriage, living arrangements, post marital residence, power relations within the domestic group, the position of the aged, the sex of the offspring, and position of the women in terms of higher education and engaging in professional work. Table 1 provides descriptions of each of the twelve variables included in the final index, as well as the hypothesized direction of association with patriarchy. Variables in the Male Domination domain include proportion of female headed households, proportion of young brides, and proportion of wives who are older than their husbands. Male headed households have been used as definition of a patriarchal governance system (Weber et al., 1947), a sociological concept also reflected in the ancient legal text of Manusmriti-a text used to formulate Hindu law by the British colonial governmentwhich states, "Her father protects her in childhood, husband protects her in youth and her sons protect her in old age; a woman is never fit for independence" (Davis Jr, 2010). Female headed households remain a minority across India (Bose, 2006), and this variable thus measures gender inequality and power dynamics at the household level. The proportion of young brides is important because in India, daughters are considered as 'paraya dhan', meaning that daughters neither contribute income nor the offspring of a father's natal group (Malhotra et al., 1995). Once married, daughters traditionally leave their natal homes, removing parents' responsibility for caring for their daughters. Age at marriage is important indicator in the context of women's autonomy as younger brides are more likely to be passive in the areas where parents-in-law seek to limit women's 


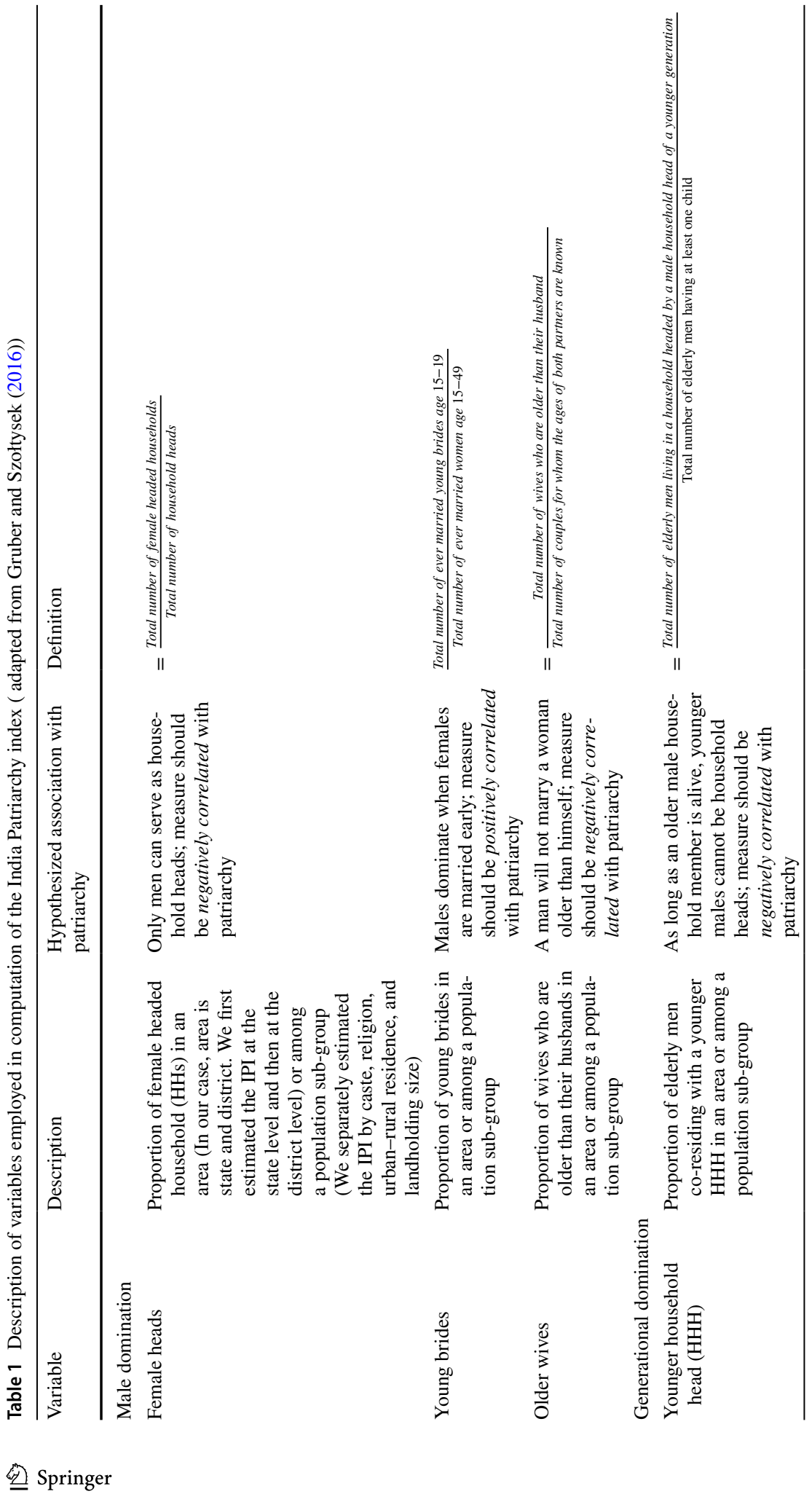




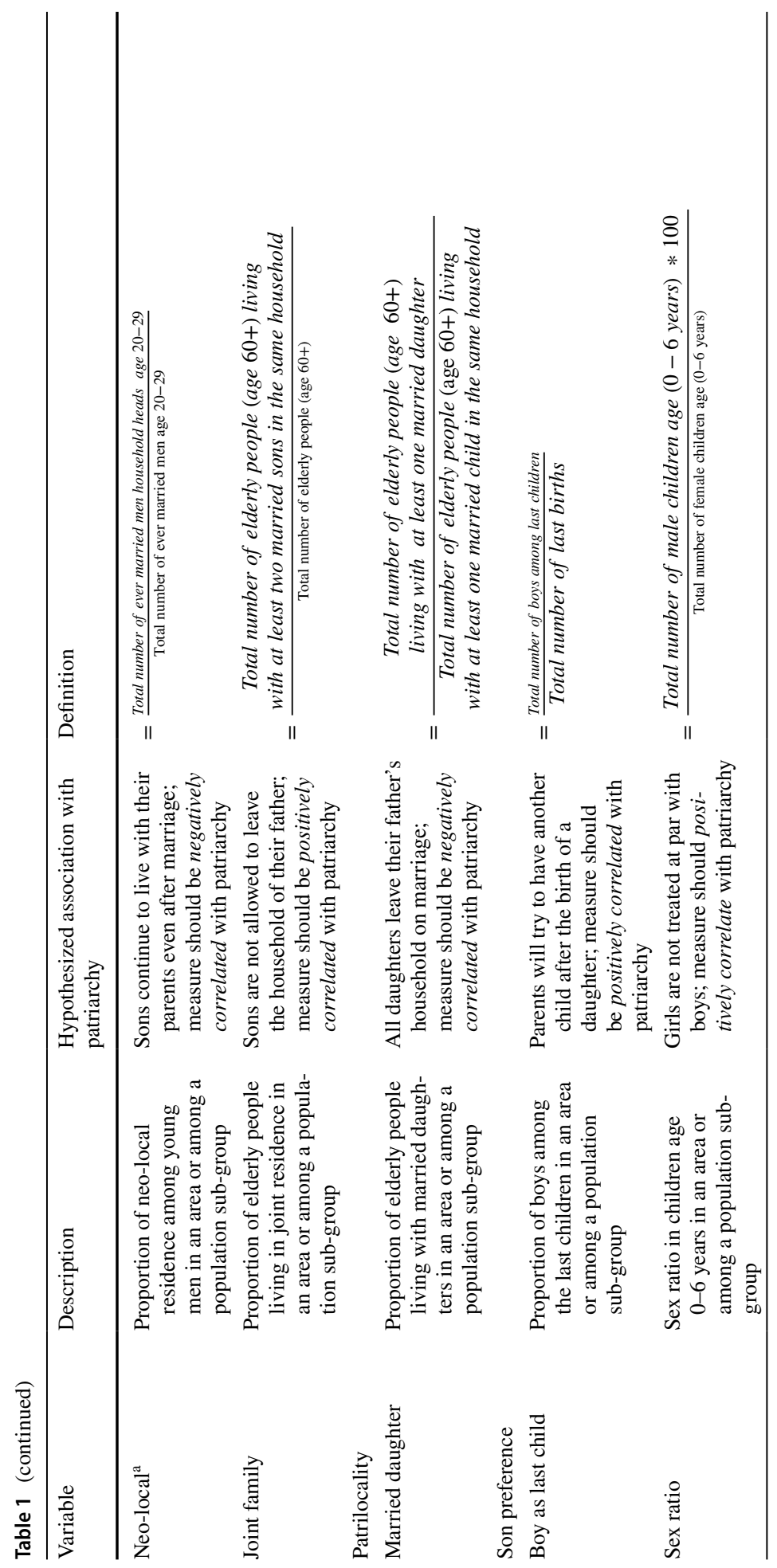




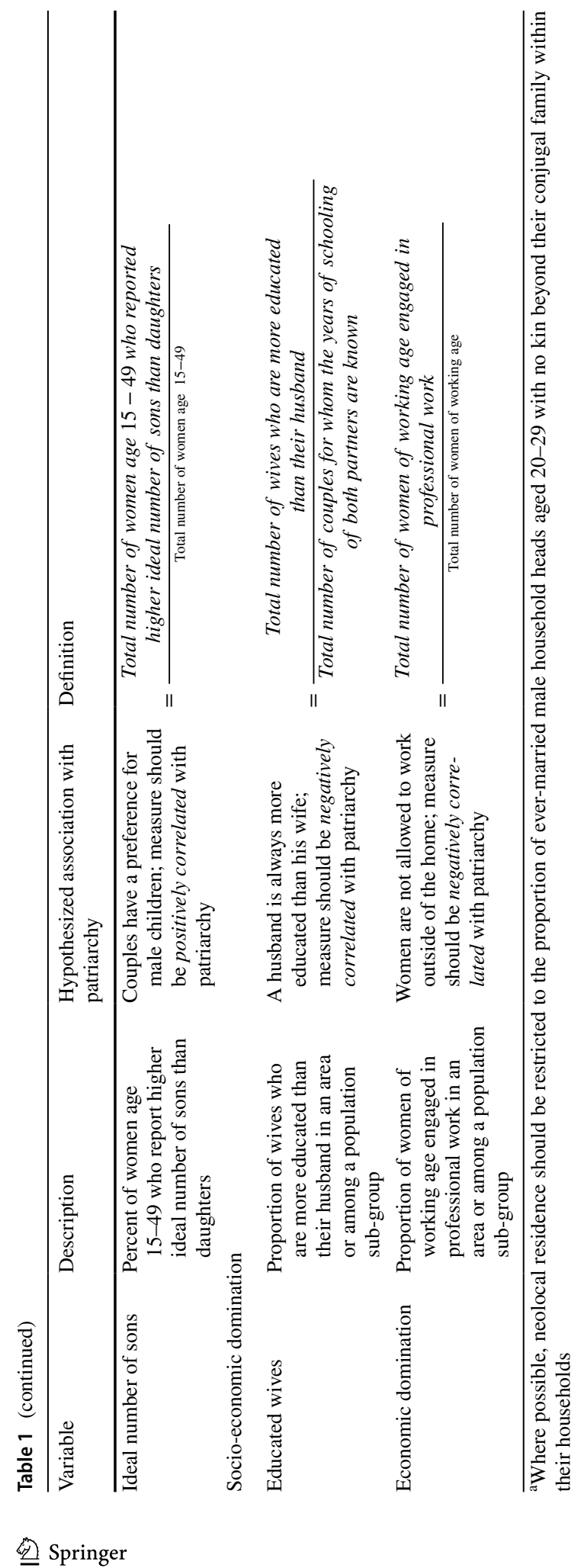


power in the household (Desai \& Andrist, 2010). The presence of older wives is unusual in Indian society, in which wives are generally younger than husbands. Male-skewed age gaps are an indication of patriarchal family systems as well as relationship equality (Cain, 1993; Putte et al., 2009); this pattern of age differences has been noted since Vedic times (Kapadia, 1966).

The second domain, Generational Domination, includes the proportion of elderly men co-residing with a younger household head, proportion of neo-local residence among young men, and proportion of elderly people living with married sons. The presence of younger household heads should be inversely reflective of patriarchy, as seniority plays a crucial role when determining household authority in India. A younger man cannot be the household head if an older man is alive. This is typical of a patriarchal system observed in other parts of the world (Engelen \& Wolf, 2005; Gruber \& Szołtysek, 2016; Halpern et al., 1996; Ruggles, 2015; Szołtysek, 2016). Neo-local residence occurs when sons establish their own independent households after their marriage. Indian sons are permitted to establish their own independent households only under exceptional circumstances. Joint family residences occur when elderly parents (age 60+ years) live with at least two married sons in the same household.

The third domain, Patrilocality, includes just one variable: the proportion of elderly people living with married daughters. Patrilocality, in which women move to the household of their husbands, is practiced throughout India, with the exception of some parts of northeast and south India (Van Ham \& Stim, 2000).

The fourth domain, Son Preference, consists of three variables: proportion of boys among the last birth, sex ratio in youngest age-group, and percent of women who reported higher ideal number of son(s) than the ideal number of daughter(s). The proportion of boys as last births represents son preference, as in a typical patriarchal system, couples will try to ensure at least a desired number of sons in their households. In India, couples are more likely to stop childbearing after having a son than daughter (Chaudhuri, 2012). Sons are critical to families in India in a number of ways, including continuity of the lineage, performing ritual rites and providing support to older family members (Das Gupta et al., 2003). India is well-known for its distorted sex ratio among young children. Couples with deep-rooted patriarchal norms generally opt for more sons then daughters (Das Gupta et al., 2003; Roberts \& Montgomery, 2016; Sen, 1990). The ideal number of male vs. female children is likely indicative of son preference at the household level (Bhat \& Zavier, 2003).

The fifth domain, Socio-economic Domination, includes two variables: proportion of wives who are more educated than their husbands and proportion of working age women engaged in professional work. Couples in which wives are more educated than their husbands are unusual in patriarchal societies, where prospective brides are generally preferred to have a lower educational level than their husbands (Fuller, 2003). A study exploring dowry in the Indian context suggested that more educated brides compete in a smaller market for grooms, as social norms typically require the groom to be more educated than the bride (Dalmia \& Lawrence, 2004). In India, women are still expected to marry those with higher education than themselves; women who marry a man with lower education are consider gender-deviant (Lin et al., 2020). The proportion of working age women engaged in professional work is important, as in truly patriarchal societies women will not be encouraged to join the labor force outside their homes. Studies have shown that a major source of women's economic value derives from their participation in work outside home (Malhotra et al., 1995). Past studies from India indicate that women from the upper castes, which were considered more patriarchal, were not allowed to work outside home (Chakraborty \& Kim, 2010). 


\subsection{Calculation of the India Patriarchy Index}

The aforementioned 12 variables were calculated at the population level for all the states of India in each of the three survey rounds. Following the methodology suggested by Gruber and Szołtysek (2016), index points for each variable were calculated according to the formula:

$$
\text { Index point }=\text { Round }\left(10 \times \frac{\text { proportion for a state }}{\text { highest proportion seen among the states included in the analysis }}\right) \text { for varia- }
$$
bles positively correlated with patriarchy.

$$
\text { Index point }=10-\text { Round }\left(10 \times \frac{\text { proportion for a state }}{\text { highest proportion seen among the states included in the analysis }}\right) \text { for }
$$
variables negatively correlated with patriarchy.

Index point $=$ Round $(10 \times(($ proportion for a state - defined minimum value $) /$ (highest proportion seen among the states included in the analysis - defined minimum value))) for the variables-proportion of boys among the last children and sex ratio in youngest age-group - under the son preference domain. These are calculated differently as they have different range. Here the minimum considered are 0.51 for the proportion of boys among the last children and 105 for the sex ratio of the youngest age-group. These minimums are considered to be biologically normal and are derived from global estimates (Bongaarts, 2013; Dyson, 2012). Note that all the proportions below these values are set to these defined minimum values.

The index points for each variable range from 0 to 10 . Then the index points of different measures included in each domain are summed to get the index point of each of the five domains. Scores of zero and 10 indicate lowest and highest degree of patriarchy, respectively. Finally, index points for the five domains are summed to get the final India Patriarchy Index score using the following formula:

$$
\begin{aligned}
\text { India Patriarchy Index }= & \frac{\text { Index of male domination }}{3} \\
& +\frac{\text { Index of generational domination }}{3} \\
& +\frac{\text { Index of patrilocality }}{1} \\
& +\frac{\text { Index of son preference }}{3} \\
& +\frac{\text { Index of socio }- \text { economic domination }}{2}
\end{aligned}
$$

Using the same methodology, we calculated the India Patriarchy Index score across select socio-economic groups such as caste, religion, urban-rural residence, and landholding size.

\subsection{Internal Consistency (i.e., Reliability) of Constructed India Patriarchy Index}

An important concern while developing an index is its reliability: whether its components are consistent with one another, can be reproduced using a similar methodology, and yield similar outcomes. We estimated Cronbach's Alpha to check the reliability of the constructed index. A coefficient value $\geq 0.60$ is considered highly reliable (Nunnally \& Bernstein, 1994). 


\subsection{Construct Validity of the India Patriarchy Index}

To assess construct validity of our Index, we estimated Pearson's correlation coefficient between the constructed India Patriarchy Index and three gender equality and empowerment indices used in India at the state and national levels: the GDI, the WEI, and the GVI. The UN GDI assess gender differences in life expectancy, education, and estimated earned income, but not absolute vulnerabilities faced solely by women and girls such as those related to reproduction (UNDP, 2019). Consequently, the UN guided a shift toward use of the Gender Inequality Index (GII), which assess gender disadvantage (e.g., reproductive health, education, political leadership, labor force participation), but this has received less use in India due to the limited set of indicators included in the measure. Hence, we instead included two indices recognized by the Government of India that focus more on women's empowerment, inclusive of indicators on sex differences and those on absolute vulnerabilities. The WEI was developed in 2017 to focus more on social and economic positioning, as well as safety from violence (Bansal, 2017), the latter indicator an important element of empowerment lacking from GII and GDI. Items in this index assess women's household decision-making control, employment, home/ land ownership, financial inclusion, and digital connectivity, as well as their experiences of marital violence and access to menstrual hygiene supplies (Bansal, 2017). The GVI was also created in 2017 as a policy tool to highlight vulnerabilities for women and girls across the life span in the areas of education, health and survival, poverty, and protection (safety from violence) (Plan-India, 2017). Comprised of 170 indicators, this is a very comprehensive measure developed for India and designed to capture gender vulnerability at the state and national levels. None of these indices were designed to capture patriarchy, or indicators of men's greater status and control over women, although some indicators are included across our indices of focus.

Given the small sample size of our study, we estimated 95\% confidence interval for each of the correlations using bootstrap resampling.

\subsection{Spatial Analysis of the India Patriarchy Index}

We calculated the India Patriarchy Index for all the 640 districts (as per the 2011 Indian Census) of India using NFHS-4. We used ArcGIS to map and examine the spatial patterns of our index across the districts of India. The shape files created in ArcGIS were later exported to GeoDa to estimate spatial statistics such as Moran's I (an indicator of global spatial autocorrelation) and Local Indicators of Spatial Association (LISA). We calculated the Moran's I to examine the spatial autocorrelation in the India Patriarchy Index at the district level. Moran's I is the Pearson coefficient measure of spatial autocorrelation. Spatial autocorrelation measures the degree to which data points are similar or dissimilar to their spatial neighbors. Moran's I is given by:

$$
\text { Moran' }^{\prime} I=C \times \frac{\sum_{i j} w_{i j} \times z_{i} \times z_{j}}{\sum_{i} z_{i}^{2}}
$$

$Z_{i}$ : standardized variable of interest at places $i$ and $j$; $W_{i j}$ : weight matrix; $C$ is the ratio of total spatial units and the sum of all spatial weights. 
Table 2 Descriptive statistics for variables used in the construction of the India Patriarchy Index, 2015-16

\begin{tabular}{llrrrr}
\hline Domain & Variables & Mean (percent) & SD & Min & Max \\
\hline Male domination & Female household head & 14.6 & 4.9 & 8.6 & 29.5 \\
& Young brides & 17.3 & 7.6 & 4.4 & 32.3 \\
& Older wives & 1.8 & 3.6 & 0.4 & 18.3 \\
Generational domination & Younger HHH & 21.7 & 7.4 & 2.4 & 28.9 \\
& Neo-local & 35.8 & 10.2 & 17.2 & 58.7 \\
& Joint family & 7.4 & 2.1 & 2.6 & 10.3 \\
Patrilocality & Married daughter & 13.9 & 12.7 & 3.9 & 74.1 \\
Son preference & Boy as last child & 60.9 & 4.9 & 49.6 & 69.8 \\
& Sex ratio (M/F *100) & 108.4 & 4.6 & 96.4 & 120.1 \\
& Ideal no. of sons & 18.9 & 7.7 & 4.8 & 37.2 \\
Socio-economic domination & Higher educated wives & 22.7 & 7.9 & 11.3 & 51.4 \\
& Women professional & 4.8 & 3.7 & 2.7 & 15.3 \\
\hline
\end{tabular}

Negative values indicate negative spatial autocorrelation, and positive values indicate positive spatial autocorrelation. Positive autocorrelation means that points with similar attribute values are closely distributed in space whereas negative spatial autocorrelation means that closely associated points are more dissimilar. Values of Moran's I range from -1 (indicating perfect dispersion) to +1 (perfect correlation). A zero value indicates a random spatial pattern (Moran, 1950).

To examine spatial clustering of low and high patriarchy districts, we estimated univariate Local Indicator of Spatial Association (LISA) maps. LISA measures the correlation of neighborhood values around a specific spatial location. It determines the extent of spatial non-stationarity and clustering present in the data. The cluster map is a special choropleth map showing those locations with a significant local Moran statistic classified by the type of spatial correlation: bright red for high-high (e.g. a district with high district-level India Patriarchy Index value is surrounded by districts with high districtlevel India Patriarchy Index values) associations, bright blue for low-low, light blue for low-high and light red for high-low. The high-high and low-low suggest clustering of similar values (often termed hot spots and cold spots, respectively), whereas high-low and low-high locations indicate spatial outliers (Anselin et al., 2006). We used Queen Contiguity Weights to estimate Moran's I and LISA. The p-values for LISA statistics were obtained from GeoDa.

All analysis except the spatial analyses were conducted using STATA 15.1.

\section{Results}

\subsection{Descriptive Statistics of Variables used in the Construction of India Patriarchy Index}

Descriptive statistics of the variables included in the India Patriarchy Index in NFHS-4 are provided in Table 2. Female headed households comprise $15 \%$ of households in India. Of households with ever-married women (aged 15-49 years), 17\% of households 


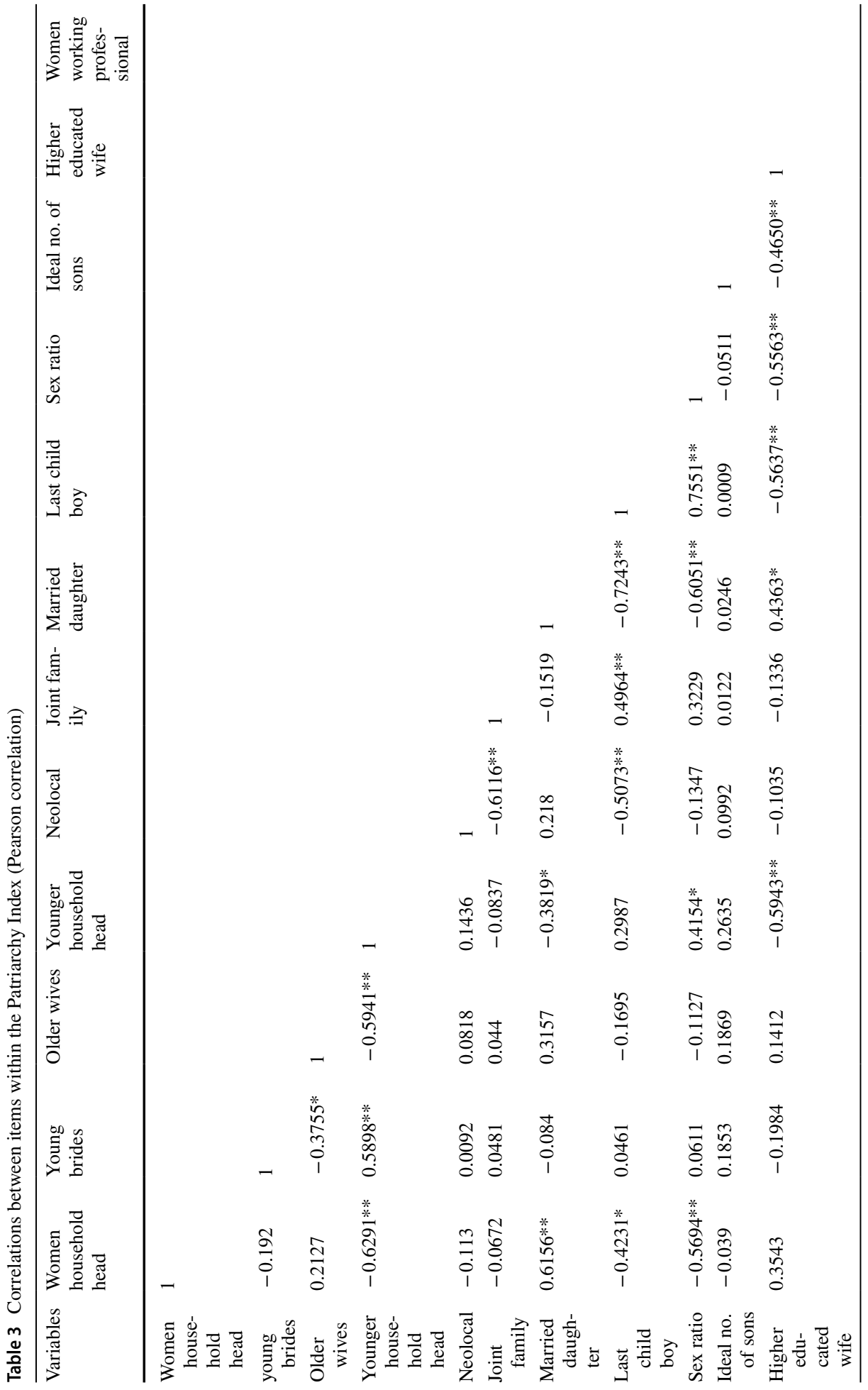




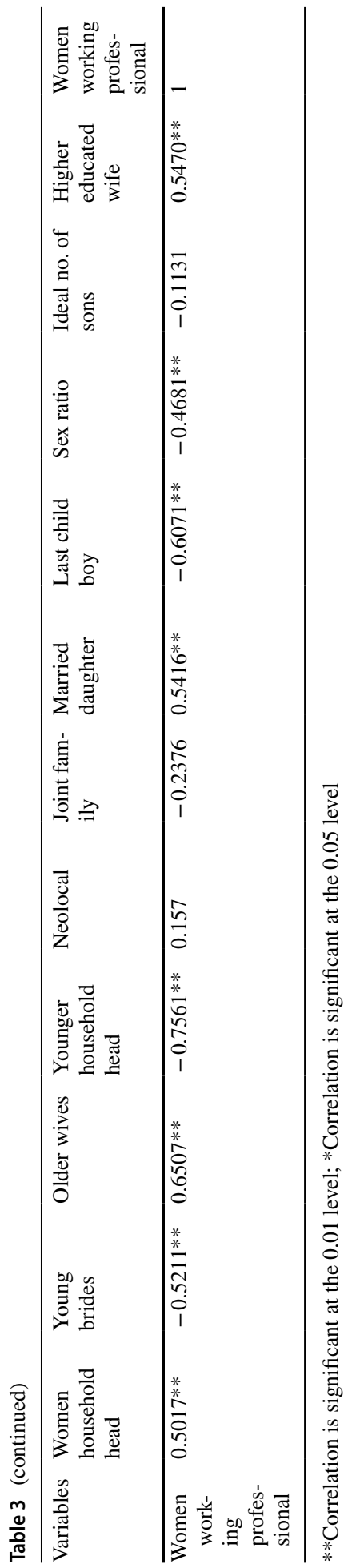

글 Springer 
Table 4 Correlations between sub-indices of patriarchy index

\begin{tabular}{|c|c|c|c|c|c|}
\hline Patriarchy domains & Male domination & $\begin{array}{l}\text { Generational } \\
\text { domination }\end{array}$ & Patrilocality & Son preference & $\begin{array}{l}\text { Socio- } \\
\text { economic } \\
\text { domination }\end{array}$ \\
\hline Male domination & 1 & & & & \\
\hline Generational domination & -0.0673 & 1 & & & \\
\hline Patrilocality & $0.4275 *$ & -0.0728 & 1 & & \\
\hline Son preference & -0.1013 & 0.1649 & $-0.5315^{* *}$ & 1 & \\
\hline $\begin{array}{l}\text { Socio-economic domina- } \\
\text { tion }\end{array}$ & 0.1034 & $-0.4750 * *$ & $0.5234 * *$ & $-0.7673^{* *}$ & 1 \\
\hline
\end{tabular}

$* *$ Correlation is significant at the 0.01 level; *Correlation is significant at the 0.05 level

had women married between the ages of 15 and 19 . Only $2 \%$ of wives were older than their husbands. About $22 \%$ of elderly men co-resided with a younger household head. Percentage of neo-local residence among young men was $36 \%$. Only $7 \%$ of elderly were living in joint residence. About $14 \%$ of elderly were living with their married daughters. In our sample, $61 \%$ of last children were sons, sex ratio in youngest age-group was 108 , and $19 \%$ of women reported higher ideal number of sons than daughters. Twenty-three percent of wives were more educated than their husbands. Only 5\% of women were engaged in professional work.

Correlations between the 12 variables included in the India Patriarchy Index are shown on Table 3. Generally, the correlations were in expected direction. The five domains were correlated, and only the domain of generational domination had lower correlation coefficients (Table 4).

\subsection{Reliability of India Patriarchy Index}

The Cronbach's alpha for the constructed India Patriarchy Index was 0.77; which indicates high internal consistency between the 12 measures.

\subsection{Validation of the India Patriarchy Index}

Figure 1 shows the correlation between the three selected gender equality and empowerment indices and the India Patriarchy Index to test construct validity. As shown, all the three indices -WEI, GVI, and GDI-are negatively correlated with the India Patriarchy Index. Correlation coefficients range between -0.63 for GVI and -0.74 for WEI. These figures indicate, as hypothesized, an inverse relationship between patriarchal norms and gender equality/empowerment in India, supporting indication of construct validity.

\subsection{India Patriarchy Index: State, Temporal, and Socio-Economic Variations}

Figure 2 shows index scores for different states of India in NFHS-4 to highlight spatial variation on this Index in India. Of the 28 states and 2 union territories, while Meghalaya depicts the lowest level of patriarchy, Haryana, a state from the north of India, depicts the highest level of patriarchy. Kerala, a state from the south that has one of best social 

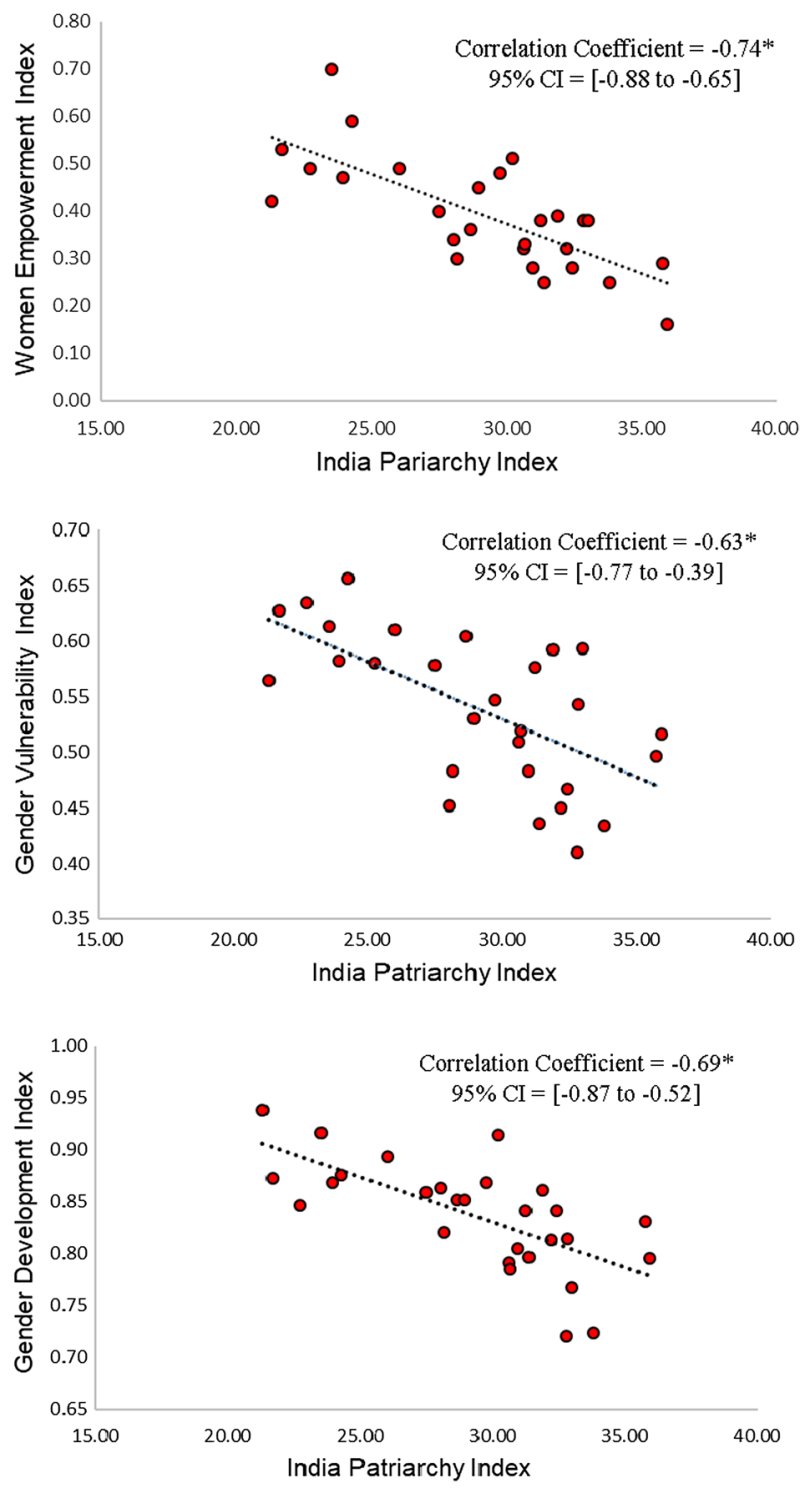

Fig. 1 Correlation between the India Patriarchy Index and selected three indices of female wellbeing, 201516. $* p<0.05$

development indicators, occupied the fourth rank on the India Patriarchy Index. Rajasthan in the north-west region ranked the second highest in level of patriarchy. Uttar Pradesh, again from the north of India, ranked third highest. Punjab ranked the fourth highest. Remember that the higher the rank, higher is the level of patriarchy in that state. The India Patriarchy Index scores ranged between 16 (Meghalaya) and 36 (Haryana). The score for India was 31. 


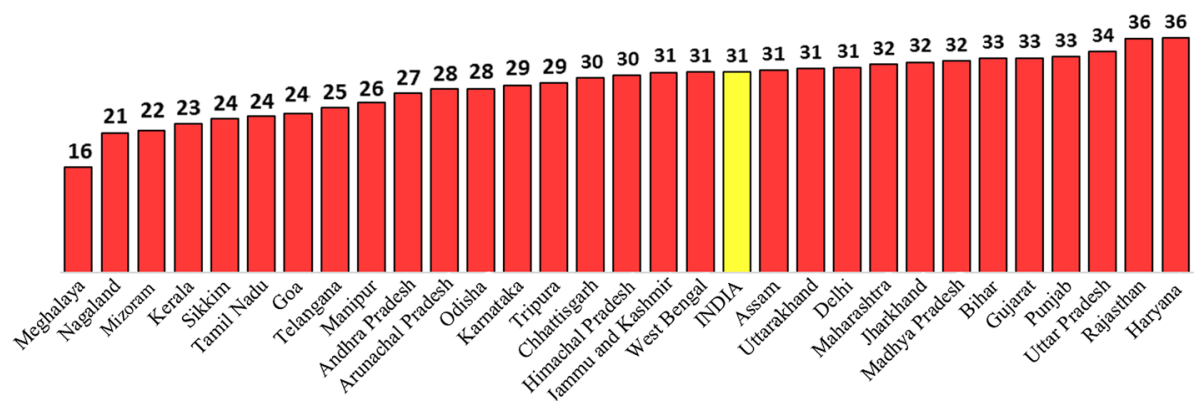

Fig. 2 Ranking of 28 states and 2 union territories on India Patriarchy Index, NFHS-4

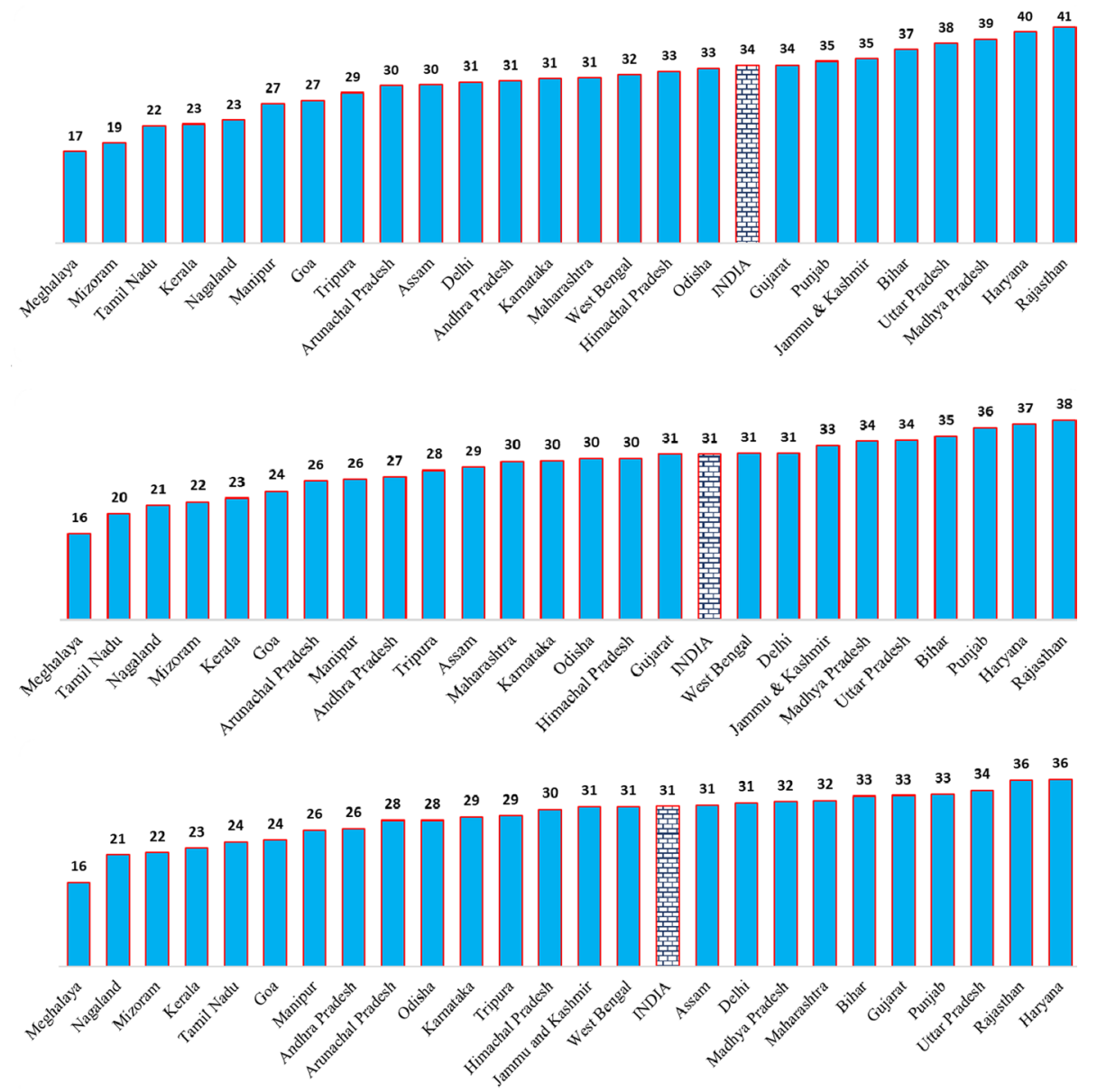

Fig. 3 Ranking of states and 2 union territories on India Patriarchy Index for NFHS-1, NFHS-3, and NFHS-4. Note Bihar and Jharkhand were merged together in NFHS-3 and NFHS-4 to make it comparable to Bihar in NFHS-1. Likewise, Uttar Pradesh and Uttarakhand were merged together in NFHS-3 and NFHS-4. Similarly, Madhya Pradesh and Chhattisgarh were merged together in NFHS-3 and NFHS-4 

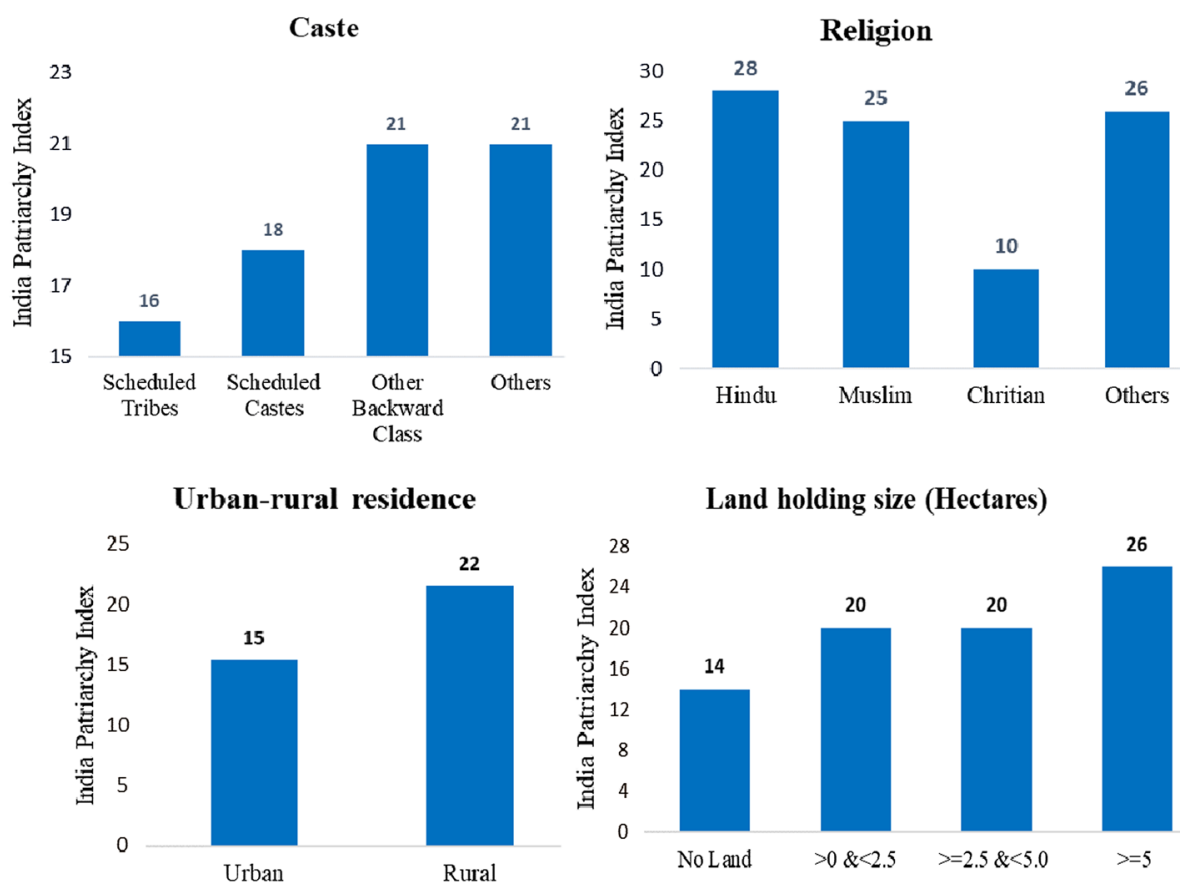

Fig. 4 India Patriarchy Index ranking by key socio-economic variables, NFHS-4. Note A higher value of the India Patriarchy Index implies higher levels of patriarchy

Figure 3 shows the ranking of states and 2 union territiroes in NFHS-1, NFHS-3, and NFHS-4. The overall national score on the India Patriarchy Index changed from 34 to 31 between NFHS-1 and NFHS-3. However, it remained unchanged between NFHS-3 and NFHS-4. Meghalaya depicts the least level of patriarchy in all the three survey rounds. While, Rajasthan ranked the highest in level of patriarchy in NFHS-1 and NFHS-3, Haryana ranked highest in NFHS-4. While Haryana ranked second highest in NFHS-1 and NFHS-3, Rajasthan ranked second highest in NFHS-4. Kerala, which occupied fourth rank on the India Patriarchy Index in NFHS-1, moved to fifth and fourth ranks in NFHS-3 and NFHS-4 respectively. The southern states, known to do better in terms of socio-economic and demographic development, fared better on the India Patriarchy Index compared to the northern, central, and western Indian states. For example, in NFHS-4, Kerala, Tamil Nadu, Andhra Pradesh, and Karnataka ranked 4nd, 5th, 8th, and 11th respectively, while Punjab, Uttar Pradesh, Rajasthan, and Haryana occupied the 22nd, 23th, 24th, and 25th rank. Bihar is the only state from eastern India that scored higher on patriarchy compared to the all-India average in all the three surveys. Interestingly, Tamil Nadu, a progressive south Indian state, slipped from 3rd rank in NFHS-1 to 5 th rank in NFHS-4.

Past studies have shown that the notion of patriarchy in India might also vary by caste, religion, and urban-rural residence. Our analysis shows that the India Patriarchy Index does indeed vary by these variables (Fig. 4). The India Patriarchy Index varied considerably by caste; the index value was lowest for Scheduled Tribes and highest for those who do not belong to Scheduled Castes, Scheduled Tribes or Other Backward Class. Likewise, 
the level of patriarchy also varied by religion. The India Patriarchy Index was highest for Hindus followed by those who do not belong to Hindu, Muslim or Christians. It was lowest among Christians. India Patriarchy Index scores were considerably higher in rural than in urban areas.

In addition, past studies have also shown that the notion of patriarchy in India might vary by the landholding size of the households. Our analysis shows that the India Patriarchy Index indeed varied by the landholding size of the households (Fig. 4). While, the India Patriarchy Index value was lowest for households having no land, it was highest for households having 5.00 hectares or more land.

\subsection{Results from District-Level Spatial Analysis of the India Patriarchy Index}

Figure 5a shows the spatial distribution of the India Patriarchy Index across the 640 districts of India surveyed in NFHS-4. Very high and high values of India Patriarchy Index were seen primarily in the districts of Rajasthan, Haryana, Madhya Pradesh, Gujarat, Maharashtra, Bihar, Jharkhand, Punjab, Uttarakhand, and Uttar Pradesh. In contrast, very low and low values of India Patriarchy Index were seen primarily in the districts of Kerala, Tamil Nadu, and north-eastern India. The Moran's I value was 0.61 which indicates strong spatial autocorrelation in the India Patriarchy Index across the districts of India. A LISA map, which shows localized spatial clustering, is shown in Fig. 5b. High-high values were predominately clustered in districts of Rajasthan, Haryana, Uttar Pradesh, Bihar, Madhya Pradesh, Bihar, Jharkhand, and Maharashtra. The low-low patriarchy values were clustered predominantly in the districts from Kerala, Tamil Nadu, and Karnataka. A few districts from Jammu \& Kashmir and north-eastern India also depicted low-low values of the India Patriarchy Index.

\section{Discussion}

This study documents the internal reliability and validity of the India Patriarchy Index, designed to quantify household level relational imbalances due to sex that disadvantage women and girls, an approach not seen in existing global indices on gender equality and empowerment. Building on work from Gruber and Szołtysek (2016), this index has been adapted to the Indian context, and is comprised of indicators on (1) male domination of men over women in nuptiality and household positioning, (2) generational domination of the older generation over the younger generation, (3) patrilocality, (4) son preference, and (5) socio-economic domination, the last of which was not included in the European Index. Validity of this newly developed India Patriarchy Index was demonstrated by its association with three indices on gender equality and empowerment (WEI, GVI, and GDI), which assess women's social positioning, safety, and well-being, but not patriarchy per se. Hence, the India Patriarchy Index can provide an additional lens through which to understand women's empowerment and gender equity in different communities across India. Importantly, these indicators are available via most Demographic and Health Survey data, 
Fig. 5 a Spatial distribution of the India Patriarchy Index across the 640 districts of India, 2015-16. b Univariate LISA map depicting the spatial clustering of the India Patriarchy Index, 2015-16. Note For POK and Rann of Kutch, average of the adjoining districts has been considered

which means that many LMICs would be able to construct a locally contextualized Patriarchy Index, though the India Patriarchy Index may be particularly useful in other South Asian settings with similar social values and norms surrounding issues of son preference and socioeconomic power imbalances. Broader application of patriarchy indices would allow for more comprehensive assessment of gender equality and empowerment at a global scale. Further, because the nature of the Demographic and Health Survey-known as the National Family Health Survey in India-offers representative data sub-nationally and over time, geographic and time variability on this index is also available, and as seen in our study, offers important insight into variations by space and time.

Within the context of India, this Index allows for a ranking of the different states of India on the issue of patriarchy for the first time, while simultaneously allowing us to see temporal trends in our spatial analyses. Findings at the national level demonstrate little change in the level of patriarchy across the past three decades, with geographic variation such that certain states maintain greater lag on this issue over time. States from the northern and western regions of India depicted higher levels of patriarchy. Haryana, a north Indian state known for poorer gender indicators, ranks highest in the nation on our India Patriarchy Index. Haryana is a largely agrarian society, and agrarian societies tend to see kinship, family and marriage relationships holding a strong influence on day to day life, as economic viability and transference is built on these (Dyson \& Moore, 1983). Haryana is also the state known for khap panchayats - extra judicial bodies—-that police marriage thereby enforcing traditionally held kinship norms and territorial exogamy (Bharadwaj, 2012; Kukreja, 2017). Rajasthan in the north-western region, known for Rajput warriors, nomadic and tribal communities adhering to traditional customs including young and mass marriages, and sati (Unnithan, 1991), ${ }^{1}$ ranked the second highest in level of patriarchy. Khap panchayats also function in Jat dominated areas of western Uttar Pradesh and parts of Rajasthan. The word khap was actually used for the first time in Rajasthan in the context of Rajput ruling class during the medieval period (Sadiq and Khan 2015). Uttar Pradesh ranked the third highest in NFHS-4, fifth highest in NFHS-3, and fourth highest in NFHS1. In contrast, Meghalaya, a north-eastern state known for its matrilineal structure (Bhutia \& Liarakou, 2018; Chakraborty \& Kim, 2010; Roy, 2018; Subba \& Ghosh, 2003), sees the lowest level of patriarchy. Kerala, in the South, also has communities ${ }^{2}$ which followed a matrilineal system in the past, and this state has some of the highest rates of education in the country (Centre for Development Studies, 2005; Chakraborty \& Kim, 2010; Jeffrey, 1992; Pillai, 2016); it occupied the 4th rank in NFHS-1 and 5th rank in NFHS-3, and 4th rank in NFHS-4. States from the southern region depicted lower levels of patriarchy. These findings are in line with the findings of sociological literature which also indicates lesser patriarchy in this region (Agarwal, 1994; Chakraborty \& Kim, 2010; Dyson \& Moore, 1983; Karve, 1953). Studies have shown that patriarchy is closely related to gender division of labor (Durkheim, 1933; Engels, 1884) and this may explain the geographic variation in our findings. In the north, where the average landholding size is big, agriculture is mechanized, and wheat is predominantly cultivated. Hence, women's involvement in

\footnotetext{
1 The patriarchal symbol of widow immolation on the funeral pyre of the husband.

2 If the Nairs were matrilineal throughout Kerala, Ezhavas, Tiyas, Brahmins, Pulayas, Christians and Muslims practiced matrilineal descent in specific regions.
} 


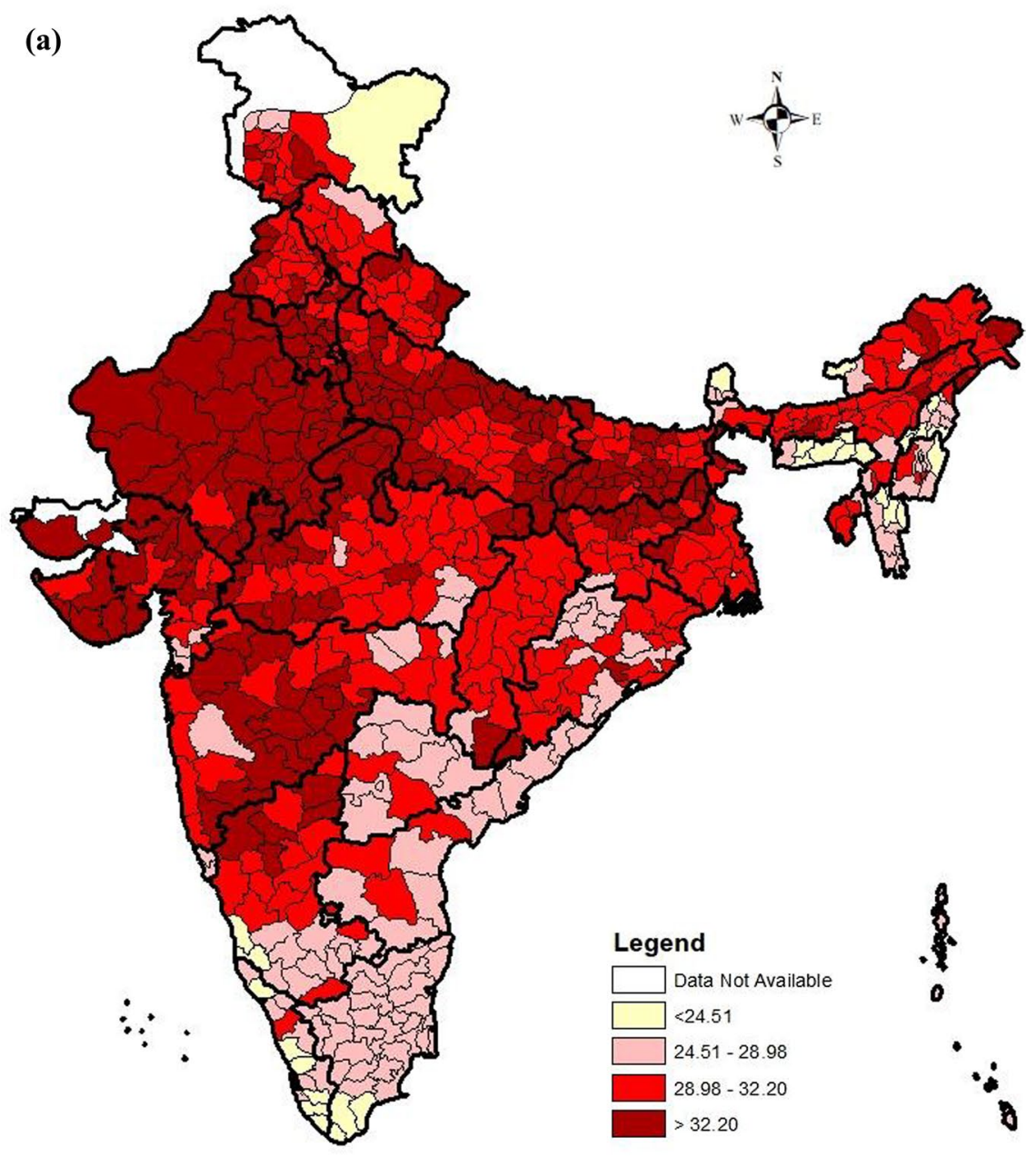

(b)
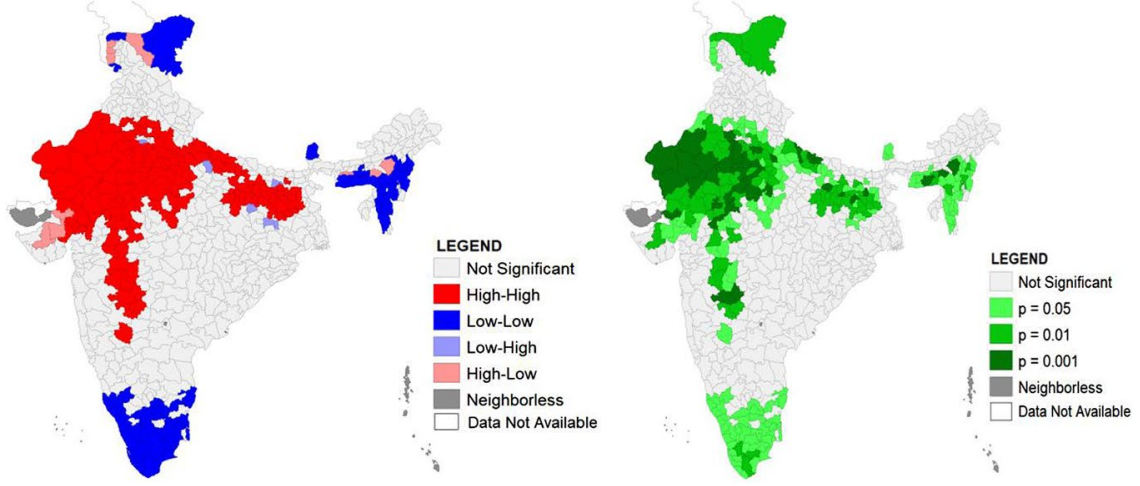
agriculture or outside the home is limited. Whereas, in the south and to some degree in the east, agriculture is more labor intensive because of rice cultivation, and women's involvement in agriculture is high. Consequently, the value of women's work for economic contribution is greater, and this may affect patriarchal norms in the south (Jeffrey et al., 1988; Miller, 1981; Moore, 1973; Sharma, 1980; Sopher, 1980a, 1980b).

Sociological literature also suggests that kinship structure in India varies by caste, class, and religion (Karve, 1953), a finding that has held since the historical times in India, though with greater influence among the upper castes (now termed 'Others' in our variables) (Mandelbaum, 1959). In fact, research from the last century indicate higher woman's bargaining power within family or kin group among the lower castes (now SC, ST, and OBC) relative to higher castes (Gough 1956). Though we lack comparable data on this issue today, there is some suggestion that this may continue to hold true due to greater likelihood of income generation among lower relative to higher caste women (IIPS and ICF, 2017; IIPS and Macro International, 2007). Women from lower castes earned a significant proportion of family income, whereas upper caste women were not allowed to work outside the home (Chakraborty \& Kim, 2010). Sociological literature also indicates significant differences in kinship structures and inheritance rules between the Hindus and Muslims of India. Nasir and Kalla (2006) reported that Muslim kinship system shared similarities with the southern system, where cross-cousin marriages and women's property inheritance were allowed. Our findings indeed suggest higher patriarchy levels among upper castes (i.e. those who do not belong to SC, ST or OBC) and Hindus compared with their counterparts. Our study also indicates higher patriarchy in rural than in urban areas. This finding is also in line with previous literature that suggests that societies that largely depend on land for their livelihoods are more likely to firmly hold the kinship ideals compared with their counterparts (Arokiasamy, 2007; Bagchi, 1981; Chakraborty \& Kim, 2010). Notably, a central belief in eco-feminist theory is that "male ownership of land has led to a patriarchal structure in society" (Larsen, 2011; Thomas-Slayter \& Rocheleau, 1995). Importantly, our refined India Patriarchy Index includes these issue of socio-economic domination, key elements not seen in the original European Patriarchy Index, that may be particularly relevant in LMIC settings where agrarian cultures still predominate and have heavy influence on the gendered norms that maintain patriarchy in these cultures.

We also find evidence for the landholding-patriarchy relationship. Our analysis indeed suggests that the notion of patriarchy varies considerably by the size of household landholdings-households having 5 hectares or more of landholding had a much higher India Patriarchy Index value compared with households having no landholding. This finding is consistent with the study by Arokiasamy and Goli (2012) who found that the child sex ratio (CSR) in India consistently increased with household landholding size. Other studies from India have also documented widespread female discrimination and female feticides in areas where landholding households are dominant (Bhatnagar et al., 2005; George \& Dahiya, 1998; Harris, 2007; Kakar, 1978; Mies, 1980; Singh \& Talwar, 2014; Vishwanath, 2000, 2001, 2004). This could be due to the co-existence of patriarchy and landlordism (male land ownership) in India since the historical times (Bagchi, 1981; Mies, 1980).

Findings also demonstrate that geographic variation in the India Patriarchy Index occurs not only at the state level, but also within states. Using this index, we could identify cluster of districts that have high and low levels of patriarchy. For example, $32^{3}$ districts out of the 33 districts of Rajasthan formed one cluster of very high level of patriarchy in Rajasthan. Likewise, a cluster of very high level of patriarchy can be seen in inland western and

${ }^{3}$ Udaipur district of Rajasthan depicted high level of patriarchy. 
central Maharashtra. These findings suggest the potential social influence of patriarchal norms in geographic "hot spot" areas. Our index is also helpful in identifying clustering of high-high and low-low districts in terms of patriarchy. The clustering of high-high and low-low districts corroborates well with the Dyson \& Moore (1983) north-south divide in India; high-high clusters located mostly in northern, and western parts of India and lowlow clusters predominantly in the south. These findings demonstrate that patriarchy, rooted in social norms, is likely geographically, as well as culturally, influenced, a point further reinforced by the significant and strong spatial autocorrelation in the Index values across the 640 districts of India.

The India Patriarchy Index adds to and supplements Malhotra et al. (1995) who measured three dimensions of patriarchy-active discrimination, marriage system, and economic value of women in India. They capture the three dimensions of patriarchy using six variables: sex ratio of mortality, female literacy share, proportion of unmarried female age 15-19, excess female migration, female labor force share, and area under rice cultivation. We go beyond these six indicators and use 12 carefully measured indicators combined in one index to fully capture patriarchy. Moreover, Malhotra et al. (1995) failed to capture the marriage and kinship system in a nuanced way. The India patriarchy Index captures five closely-knit dimensions of patriarchy in India. The India Patriarchy Index provides social scientists and demographers with a unique opportunity to relate demographic as well as development indicators such as fertility, mortality, women's schooling, involvement in productive economy, violence against women, etc. with gender inequality in India. This new index may also help in better understanding of the spatial variations in demographic and development indicators in a large and diverse country like India.

While findings from this study offer important contribution to the field with regard to measurement and monitoring of patriarchy, certain limitations of the present analysis warrant consideration. Our India Patriarchy Index is specific to family structure and should not be generalized to aspects of patriarchy outside of families and households, such as political leadership. This measure is an additional tool that may be used to better equip researchers with methods to assess aspects of gender equity. Data limitations also exist in the NFHS data. All variables included in analyses are self-report and the survey was not originally designed to comprehensively assess patriarchy. That said, use of existing nationally-representative data from Demographic and Health Surveys presents the opportunity to test this measure (or local adaptations thereof) in other LMIC country contexts globally.

\section{Conclusions}

While the sociological construct of patriarchy is recognized to compromise health, economic, and social outcomes in ways that can impede women's equality and empowerment, no globally-validated indices exist on this topic, impeding our ability to track change and progress towards equality. The India Patriarchy Index offers a reliable and valid index able to assess national and sub-national levels of patriarchy for purposes of ranking and tracking progress on this key indicator across India. Further, because of the nature of the variables included in the India Patriarchy Index, comparable versions of the index can be adapted and/or replicated in other LMICs. Importantly, findings for the index in India offers three critical insights to advance the field methodologically, theoretically, and substantively. First, there is spatial variation in India Patriarchy Index scores across the country. This highlights the importance of measures such as the one employed in the present analysis 
that allows population scientists to incorporate geographic and historic context into consideration of gender equity and patriarchal norms. Second, though this link between patriarchy and gender inequality has been defined in theoretical literature, our results provide empirical evidence using a quantitative measure of patriarchy to establish this relationship in the Indian context. Finally, our development and application of an adapted, novel composite measure - the India Patriarchy Index - to routine Demographic and Health Survey data establishes its feasibility and accessibility for other countries looking to deepen their understanding of the ways in which this entrenched social system impedes progress for women.

Funding Open access funding provided by BMGF (OPP1179208).

Availability of data and materials All data is publicly available and may be downloaded from https://dhspr ogram.com.

Code availability Stata code can be requested from the authors.

\section{Declarations}

Conflict of interest The authors declare that they have no competing interest.

Open Access This article is licensed under a Creative Commons Attribution 4.0 International License, which permits use, sharing, adaptation, distribution and reproduction in any medium or format, as long as you give appropriate credit to the original author(s) and the source, provide a link to the Creative Commons licence, and indicate if changes were made. The images or other third party material in this article are included in the article's Creative Commons licence, unless indicated otherwise in a credit line to the material. If material is not included in the article's Creative Commons licence and your intended use is not permitted by statutory regulation or exceeds the permitted use, you will need to obtain permission directly from the copyright holder. To view a copy of this licence, visit http://creativecommons.org/licenses/by/4.0/.

\section{References}

Agarwal, B. (1994). A field of one's own: Gender and land rights in South Asia. Cambridge University Press.

Anselin, L., Syabri, I., \& Kho, Y. (2006). GeoDa: An introduction to spatial data analysis. Geographical Analysis, 38(1), 5-22. https://doi.org/10.1111/j.0016-7363.2005.00671.x

Arokiasamy, P. (2007). Sex ratio at birth and excess female child mortality in India:trends, differentials and regional patterns. In I. Attane \& C. Z. Guilmoto (Eds.), Watering the Neighbour's Garden: The Growing Demographic Female Deficit in India. Paris: Committee for Intern ational Cooperation in National Research in Demography.

Arokiasamy, P., \& Goli, S. (2012). Explaining the skewed child sex ratio in rural India: Revisiting the landholding-patriarchy hypothesis. Economic and Political Weekly, XLVI, I(42), 85-94.

Bagchi, D. (1981). Women in agrarian transition in India: Impact of development. Geografiska Annaler: Series B, Human Geography, 63(2), 109-117. https://doi.org/10.1080/04353684.1981.11879465

Bansal, S. (2017). Indian states and women: where are they empowered, where are they not Hindustan Times. Retrieved from https://www.hindustantimes.com/interactives/women-empowerment-index/.

Bharadwaj, S. B. (2012). Myth and reality of the khap panchayats: A historical analysis of the panchayat and khap panchayat. Studies in History, 28(1), 43-67. https://doi.org/10.1177/0257643013477250

Bhat, P. N. M., \& Zavier, A. J. F. (2003). Fertility decline and gender bias in northern India. Demography, 40(4), 637-657. https://doi.org/10.2307/1515201

Bhatnagar, R. D., Dube, R., \& Dube, R. (2005). Female infanticide in India: A feminist cultural history. State University of New York Press. 
Bhutia, Y., \& Liarakou, G. (2018). Gender and nature in the matrilineal society of Meghalaya, India: Searching for ecofeminist perspectives. The Journal of Environmental Education, 49(4), 328-335. https://doi. org/10.1080/00958964.2017.1407283

Blumberg, R. L. (1988). Income under female versus male control: Hypotheses from a theory of gender stratification and data from the third world. Journal of Family Issues, 9(1), 51-84. https://doi.org/10. $1177 / 019251388009001004$

Bongaarts, J. (2013). The implementation of preferences for male offspring. Population and Development Review, 39(2), 185-208. https://doi.org/10.1111/j.1728-4457.2013.00588.x

Bose, A. (2006). Where women prevail: 2001 census and female heads of households. Economic and Political Weekly, 41(22), 2192-2194.

Cain, M. T. (1993). Patriarchal structure and development change. In W. Position \& D. Change (Eds.), Nora Faderici, Karen Oppenheim Mason \& Solvi Sogner (pp. 43-60). Clarendon Press.

Centre for Development Studies. (2005). Human Development Report 2005. Thiruvananthapuram: Government of Kerala.

Chakraborty, T., \& Kim, S. (2010). Kinship institutions and sex ratios in India. Demography, 47(4), 9891012. https://doi.org/10.1007/BF03213736

Chaudhuri, S. (2012). The desire for sons and excess fertility: A household-level analysis of parity progression in India. International Perspectives on Sexual and Reproductive Health, 38(4), 178-186. https:// doi.org/10.1363/3817812

Dalmia, S., \& Lawrence, P. G. (2004). The institution of dowry in india: Why it continues to prevail. Journal of Developing Areas, 38(2), 71-93.

Das Gupta, M., Zhenghua, J., Bohua, L., Zhenming, X., Chung, W., \& Hwa-Ok, B. (2003). Why is Son preference so persistent in East and South Asia? A cross-country study of China, India and the Republic of Korea. The Journal of Development Studies, 40(2), 153-187. https://doi.org/10.1080/0022038041 2331293807

Davis, D. R., Jr. (2010). The spirit of hindu law. Cambridge University Press.

Desai, S., \& Andrist, L. (2010). Gender scripts and age at marriage in India. Demography, 47(3), 667-687. https://doi.org/10.1353/dem.0.0118

Durkheim, E. (1933). The division labor in society. The Macmillan Company.

Dyson, T. (2012). Causes and consequences of skewed sex ratios. Annual Review of Sociology, 38(1), 443461. https://doi.org/10.1146/annurev-soc-071811-145429

Dyson, T., \& Moore, M. (1983). On kinship structure, female autonomy, and demographic behavior in India. Population and Development Review, 9(1), 35-60. https://doi.org/10.2307/1972894

Engelen, T., \& Wolf, A. P. (2005). Marriage and the family in eurasia. Perspectives on the Hajnal hypothesis. In T. Engelen \& A. P. Wolf (Eds.), Marriage and the family in Eurasia. Perspectives on theHajnal hypothesis (pp. 15-34). Aksant, Amsterdam.

Engels, F. (1884). The origin of the family, private property and the State. Hottingen, Zurich.

Ferrant, G., \& Nowacka, K. (2015). Measuring the drivers of gender inequality and their impact on development: The role of discriminatory social institutions. Gender \& Development, 23(2), 319-332. https:// doi.org/10.1080/13552074.2015.1053221

Fuller, C. J. (2003). The renewal of the priesthood: Modernity and traditionalism in a south Indian temple. Princeton University Press.

George, S. M., \& Dahiya, R. S. (1998). Female foeticide in rural Haryana. Economic and Political Weekly, 33(32), 2191-2198.

Geske Dijkstra, A. (2006). Towards a fresh start in measuring gender equality: A contribution to the debate. Journal of Human Development, 7(2), 275-283. https://doi.org/10.1080/14649880600768660

Gough, E. K. (1956). Brahman kinship in a tamil village 1. American anthropologist, 58(5), 826-853.

Gruber, S., \& Szołtysek, M. (2016). The patriarchy index: A comparative study of power relations across historical Europe. The History of the Family, 21(2), 133-174. https://doi.org/10.1080/1081602X.2014. 1001769

Halpern, J. M., Kaser, K., \& Wagner, R. A. (1996). Patriarchy in the Balkans: Temporal and cross-cultural approaches. The History of the Family, 1(4), 425-442. https://doi.org/10.1016/S1081-602X(96) 90011-1

Harris, R. (2007). India: aryan patriarchy and dravidian matriarchy. Retrieved September, 26, 2020, from http://www.integralworld.net/harris32.html.

IIPS. (1995). National Family Health Survey (MCH and Family Planning), India 1992-93. Bombay: IIPS.

IIPS, \& ICF. (2017). National Family Health Survey (NFHS-4), 2015-16: India. Mumbai: IIPS.

IIPS, \& Macro International. (2007). National family health survey (NFHS-3), 2005-06: India: Volume I. Mumbai: IIPS.

Plan India. (2017). Plan for every child gender vulnerability index Report-1: Plan International. 
Jäger, U., \& Rohwer, A. (2009). Women's Empowerment: Gender-related Indices as a Guide for Policy CESifo DICE Report (Vol. 7, pp. 37-50). Munich: ifo Institute Leibniz Institute for Economic Research at the University of Munich.

Jayachandran, S. (2015). The roots of gender inequality in developing countries. Annual Review of Economics, 7(1), 63-88. https://doi.org/10.1146/annurev-economics-080614-115404

Jeffrey, P., Jeffrey, R., \& Lyon, A. (1988). When did you last see your mother? Aspects of female autonomy in rural north India. In J. C. Caldwell, A. G. Hill, \& V. J. Hull (Eds.), Micro-approaches to demographic research (pp. 321-333). Kegan Paul International.

Jeffrey, R. (1992). Politics, women, and well being: How Kerala became “A Model." Palgrave Macmilan.

Kabeer, N. (2015). Caste system, patriarchy working against India's gender equality. Paper presented at the International Conference on Gender Equality, Thiruvananthapuram, Kerala.

Kakar, S. (1978). The inner world: A psychoanalytic study of hindu childhood and society. Oxford University Press.

Kapadia, K. M. (1966). Marriage and family in India (Vol. Third). Oxford University.

Karve, I. (1953). Kinship organisation in India. Poone, India: Deccan College Post-graduate and Research Institute.

Krieger, N. (2011). Epidemiology and the people's health: Theory and context. Oxford University Press.

Kukreja, R. (2017). Caste and cross-region marriages in Haryana, India: Experience of dalit cross-region brides in jat households. Modern Asian Studies, 52(2), 492-531. https://doi.org/10.1017/S0026749X1 6000391

Larsen, M. (2011). Vulnerable daughters in India culture, development and changing contexts. Routledge.

Lin, Z., Desai, S., \& Chen, F. (2020). The emergence of educational hypogamy in India. Demography, 57(4), 1215-1240. https://doi.org/10.1007/s13524-020-00888-2

Littrell, R. F., \& Bertsch, A. (2013). Traditional and contemporary status of women in the patriarchal belt. Equality, Diversity and Inclusion: An International Journal, 32(3), 310-324.

Malhotra, A., Vanneman, R., \& Kishor, S. (1995). Fertility, dimensions of patriarchy, and development in India. Population and Development Review, 21(2), 281-305. https://doi.org/10.2307/2137495

Mandelbaum, D. G. (1959). Social uses of funeral rites. In H. Feifel (Ed.), The meaning of death (pp. 189217). McGraw-Hill.

Mies, M. (1980). Capitalist development and subsistence reproduction; rural women in India. Bulletin of Concerned Asian Scholars, 12(1), 2-14. https://doi.org/10.1080/14672715.1980.10405557

Miller, B. D. (1981). The endangered sex: Neglect of female children in rural north India. Cornell University Press.

Moore, M. (1973). Cross-cultural surveys of peasant family structures: Some comments. American Anthropologist, 75(3), 911-915.

Moran, P. A. P. (1950). Notes on continuous stochastic phenomena. Biometrika, 37(1/2), 17-23. https:// doi.org/10.2307/2332142

Nasir, R., \& Kalla, A. K. (2006). Kinship system, fertility and son preference among the muslims: A review. The Anthropologist, 8(4), 275-281. https://doi.org/10.1080/09720073.2006.11890976

Nunnally, J., \& Bernstein, I. (1994). Psychometric Theory (3rd ed.). McGraw-Hill.

OECD. (2019). Measures discrimination against women in social institutions. Social Institutions and Gender Index (SIGI) Retrieved Sept. 28, 2020, from https://stats.oecd.org/Index.aspx?DataS etCode=GIDDB2019

Permanyer, I. (2013). A critical assessment of the UNDP's gender inequality index. Feminist Economics, 19(2), 1-32. https://doi.org/10.1080/13545701.2013.769687

Pillai, M. S. (2016). Ivory hhrone: Chronicles of the house of travancore. Harper Collins.

Raj, A. (2017). Evidence-based measures of empowerment for research on gender equality (EMERGE). Resources: Global Indices and Indicators on Gender. from http://emerge.ucsd.edu/resources/

Roberts, L. R., \& Montgomery, S. B. (2016). India's distorted sex ratio: Dire consequences for girls. Journal of Christian Nursing, 33(1), E7-E15. https://doi.org/10.1097/cnj.0000000000000244

Roy, A. (2018). Discord in matrilineality: Insight into the khasi society in Meghalaya. Society and Culture in South Asia, 4(2), 278-297. https://doi.org/10.1177/2393861718767238

Ruggles, S. (2015). Patriarchy, power, and pay: The transformation of American families, 1800-2015. Demography, 52(6), 1797-1823. https://doi.org/10.1007/s13524-015-0440-z

Sadiq, S., \& Khan, A. (2015). Khappanchayats in India: precepts and practices. International Journal of Current Research, 7(1), 11753-11757.

Seltzer, J. A. (2019). Family change and changing family demography. Demography, 56(2), 405-426. https://doi.org/10.1007/s13524-019-00766-6

Sen, A. (1990, 12/20/1990). More than 100 million women are missing, The New York Review of Books. 
Sev'er, A. (2008). Discarded daughters: The patriarchal grip, dowry deaths, sex ratio imbalances \& foeticide in India. Women's Health and Urban Life, 7(1), 56-75.

Sharma, U. (1980). Women, work and property in North-west India. Tavistock Publications Ltd.

Singh, R., \& Talwar, U. K. (2014). Culture of missing girls: Anthropological insight in culture, medical technologies and medicine. Anthropology, 2(3), 2-10. https://doi.org/10.4172/2332-0915.100012

Sopher, D. E. (1980a). The geographical patterning of culture in India. In D. E. Sopher (Ed.), An Exploration of India: Geographical perspectives on society and culture (pp. 289-326). Cornell University Press.

Sopher, D. E. (1980b). Sex disparity in Indian literacy. In David E. Sopher (Ed.), An Exploration of India: geographical perspectives on society and culture (pp. 130-188). thaca, N.Y.: Cornell University Press.

Subba, T. B., \& Ghosh, G. C. (2003). The anthropology of north east india. New Delhi: Orient Longman.

Szołtysek, M. (2016). Rethinking East-Central Europe: Family systems and co-residence in the PolishLithuanian Commonwealth (Vol. 1). Peter Lang Press.

Szołtysek, M., \& Poniat, R. (2018a). Historical family systems and contemporary developmental outcomes: What is to be gained from the historical census microdata revolution? The History of the Family, 23(3), 466-492. https://doi.org/10.1080/1081602X.2018.1477686

Szołtysek, M., \& Poniat, R. (2018b). The power of the family: New data reveal the role of the historical family as the instigator of disparate and lasting developmental trajectories. World Values Research, $10(1), 1-39$.

Thomas-Slayter, B., \& Rocheleau, D. E. (1995). Gender, environment, and development in Kenya: a grassroots perspective. Boulder: L. Rienner.

UNDP. (2019). Gender development index human development report 2019. New York, USA: United Nations Development Programme.

Unnithan, M. (1991). Caste, tribe and gender in south Rajasthan. Cambridge Anthropology, 15(1), $27-45$.

Van de Putte, B., Van Poppel, F., Vanassche, S., Sanchez, M., Jidkova, S., Eeckhaut, M., Oris, M., Matthijs, K., \& Teachman, J. (2009). The rise of age homogamy in 19th century western Europe. Journal of Marriage and Family, 71(5), 1234-1253.

Van Ham, P., \& Stirn, A. (2000). The seven sisters of India : Tribal worlds between Tibet and Burma. Prestel Mapin Publishing Pvt. Ltd.

Vishwanath, J., \& Palakonda, S. C. (2011). Patriarchal ideology of honour and honour crimes in India. International Journal of Criminal Justice Sciences (IJCJS), 6(1 \& 2), 386-395.

Vishwanath, L. S. (2000). Female infanticide and social structure: A socio-historical study in Western and Northern India. Hindustan Publishing Corporation.

Vishwanath, L. S. (2001). Female foeticide and infanticide. Economic \& Political Weekly, 35(36), 3411-3412.

Vishwanath, L. S. (2004). Female infanticide: The colonial experience. Economic and Political Weekly, 39(22), 2313-2318.

Walby, S. (1989). Theorising patriarchy. Sociology, 23(2), 213-234.

Weber, M., Henderson, A. M., \& Parsons, T. (1947). The theory of social and economic organization. Oxford University Press.

Publisher's Note Springer Nature remains neutral with regard to jurisdictional claims in published maps and institutional affiliations. 